\title{
Achalasia Cardia Resulting in Bronchial Obstruction - A Case Series and Literature Review
}

\author{
Eric Omar Then, Tagore Sunkara ${ }^{1}$, Febin John ${ }^{1}$, Kishore Kumar Dewnani ${ }^{2}$, Andrea Culliford and Vinaya Gaduputi
}

Division of Gastroenterology and Hepatology, SBH Health System, Bronx, NY; Division of Gastroenterology and Hepatology, Mercy One Des Moines Medical Center ${ }^{1}$, Des Moines, IA; Division of Gastroenterology and Hepatology, Bronx Lebanon Hospital Center ${ }^{2}$, Bronx, NY, USA

\begin{abstract}
Achalasia is a motility disorder of the esophagus that is characterized by loss of ganglionic neurons within the myenteric plexus of the lower esophageal sphincter (LES) resulting in failure of the LES to relax. Clinically this disorder presents with simultaneous dysphagia to solids and liquids, and if left untreated, leads to esophageal dilation, which can give rise to many adverse consequences. Extrinsic compression of respiratory structures is one such consequence, and rarely, cases of tracheal compression secondary to achalasia have been reported. However, cases of extrinsic bronchial compression are yet rarer. Here, we present a case series comprised of two patients with achalasia who presented with extrinsic bronchial compression by a dilated esophagus secondary to achalasia. (Korean J Gastroenterol 2019;73:105-108)
\end{abstract}

Key Words: Esophageal achalasia; Dysphagia; Airway obstruction; Heller myotomy; Esophageal motility disorders

\section{INTRODUCTION}

Achalasia alone has an annual incidence of 1 in 100,000 worldwide, and epidemiologically, it has highest incidences in the 3rd and 7 th decades of life. ${ }^{1}$ Its pathogenesis is usually idiopathic, but cases have been reported secondary to Chagas disease and malignancy of the lower esophagus. ${ }^{2}$ The most common symptom of achalasia is simultaneous dysphagia to solids and liquids. Associated respiratory symptoms are well established and include cough, asthma, pneumonia, hoarseness, and sore throat, ${ }^{3}$ which are believed to occur secondary to regurgitation and subsequent aspiration of food into the respiratory tree. ${ }^{4}$ On the other hand, respiratory compromise is a rare manifestation of achalasia that stems from extrinsic compression of respiratory structures by a dilated esophagus.

\section{CASE REPORT}

\section{Case 1}

The first case involved a 36-year-old male with an extensive medical history of epilepsy, intravenous drug abuse, mitral valve and aortic valve replacement, prosthetic valve endocarditis (with septic emboli), chronic HCV treatment naive, empyema (post video-assisted thoracoscopic surgery), achalasia, and a wheelchair-bound status. At presentation in our institution's emergency department, he complained of dizziness of duration 3 days and denied any other complaint. Vitals signs on presentation were; temperature $37.1^{\circ} \mathrm{C}$, blood pressure of 90/60, heart rate 100 beats per minute, and oxygen saturation $92 \%$ on room air. Physical examination revealed a cachectic, wheelchair-bound young man. Notable findings included a decubitus sacral ulcer and a jejunostomy tube in place. According to the patient's wife, the jejunostomy tube

Received March 11, 2018. Revised June 1, 2018. Accepted July 7, 2018.

(C) This is an open access article distributed under the terms of the Creative Commons Attribution Non-Commercial License (http://creativecommons.org/licenses/ by-nc/4.0) which permits unrestricted non-commercial use, distribution, and reproduction in any medium, provided the original work is properly cited. Copyright (c) 2019. Korean Society of Gastroenterology.

Correspondence to: Tagore Sunkara, Division of Gastroenterology and Hepatology, The Brooklyn Hospital Center, Clinical Affiliate of The Mount Sinai Hospital, 121 Dekalb Avenue, Brooklyn, NY 11201, USA. Tel: +1-217-671-2094, Fax: +1-718-960-3218, E-mail: tagoresunkara@hotmail.com, ORCID: https://orcid.org/0000-0001-9536-9027 
was placed at another institution in preparation for unspecified surgery, but the patient was non-compliant and continued oral feeds. When obtained, records revealed the patient had been scheduled for Heller myotomy, but the procedure was not performed due to patient non-compliance. Laboratory work-up on admission revealed hemoglobin 10 $\mathrm{g} / \mathrm{dL}$, white blood cell count $15 \times 10^{9}$ per liter, and a platelet count of $213 \times 10^{9}$ per liter. His hepatic function panel was normal. Due to a history of prosthetic valves, infective endocarditis 6 months previously, and a Quick sequential organ failure assessment score for sepsis of 2 , he was empirically started on antibiotics for possible sepsis secondary to prosthetic valve endocarditis. Three hours after admission, the patient had an episode of coffee ground emesis. Repeat labs showed his hemoglobin had fallen to $6 \mathrm{~g} / \mathrm{dL}$. Based on this finding, he was transfused with one unit of packed red blood cells and scheduled for emergent upper endoscopy. No esophageal varices or gastric or duodenal ulcers were observed by upper endoscopy, but it did reveal a severely dilated esoph-

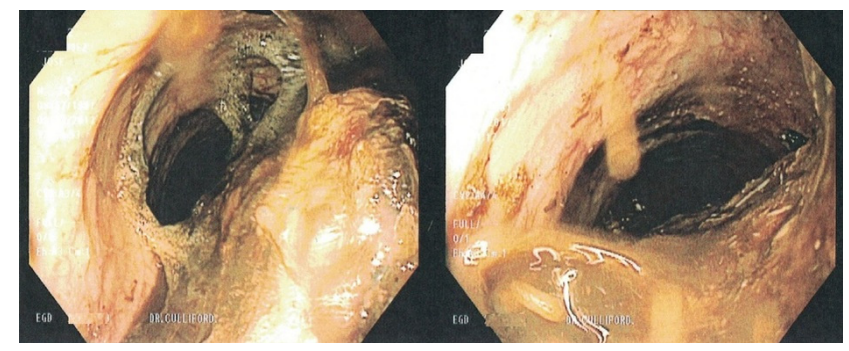

Fig. 1. Upper endoscopy showing dilated esophagus containing food.

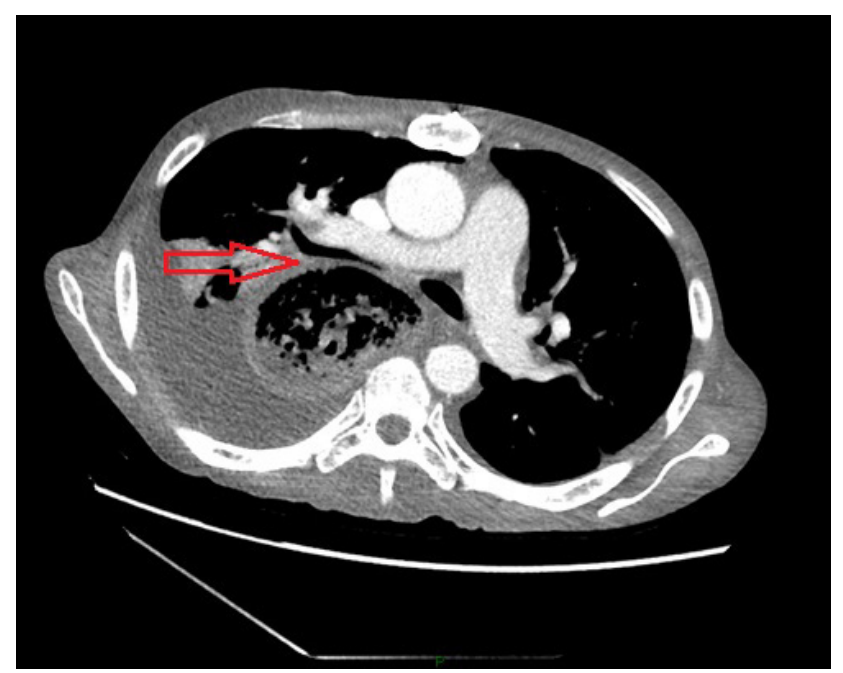

Fig. 2. CT image scan of the chest showing a dilated esophagus resulting in compressed right main stem bronchus (arrow) intermedius. CT, computed tomography. agus containing fermenting food (Fig. 1), which was diluted and removed by suction during endoscopy. After clearing the retained food from the esophagus and stomach, Los Angeles (LA) class $C$ esophagitis was noted in the middle and lower thirds of the esophagus, which was considered the likely cause of the coffee ground emesis. CT of the chest and abdomen subsequently showed a dilated esophagus resulting in compression of the right mainstem bronchus and bronchus intermedius (Fig. 2).

During his stay, the patient was uncooperative and refused further treatment or intervention and signed out against medical advice. He was readmitted one month later but subsequently expired from complications of septic shock.

\section{Case 2}

The second case was of a 58-year-old female with a medical history of hypertension, asthma, achalasia, tobacco use, and heroin (methadone) abuse who was referred to our outpatient gastroenterology clinic from SBH Health System. She presented complaining of dysphagia to solid foods and odynophagia in her middle chest of duration one year. Physical examination revealed a thin woman $\left(\mathrm{BMl} 19.4 \mathrm{~kg} / \mathrm{m}^{2}\right)$ with unremarkable findings. On interrogation, the patient reported she had undergone Heller myotomy 9 years previously and an associated 80-pound weight loss over 8 months. Chest CT, revealed a severely dilated esophagus measuring up to $7.4 \times 7.8 \mathrm{~cm}$ in maximal axial diameter and occlusion of the right middle lobe bronchus secondary to the mass effect of the dilated esophagus (Fig. 3, 4). Notably, the patient had been examined at another institution 2 years previously but had been lost to follow up. At that time, chest CT showed a large hiatal hernia with inspissated enteric contents and gastroesophageal junction stricturing. Upper endoscopy was also attempted but aborted due to retained food in the esophagus. The patients' symptoms and radiographic findings were consistent with stricturing at the site of prior myotomy with worsening esophageal dilation manifested as compression of the right middle lobe bronchus. The patient was referred to her primary institution for possible repeat surgical intervention.

\section{DISCUSSION}

The first case of respiratory failure as a complication of achalasia was reported in $1950 .{ }^{5}$ These cases are few and 
far between, but most cases present with compression of the trachea. ${ }^{6}$ Becker and Castell ${ }^{7}$ compiled 12 such cases all involving females over the age of 50 , which makes our cases rare on two counts. First, our patients presented with compression of the right mainstem bronchus and right middle lobe bronchus, respectively, and secondly, these findings were purely incidental as they had no active symptoms of respiratory compromise.

Early diagnosis of achalasia is essential for preventing the development of compression of respiratory structures. Diagnostic modalities include barium swallow, esophagogastroduodenoscopy, and esophageal manometry. Barium swallow is usually used first in suspected cases and will show a dilated proximal esophagus with distal narrowing, known as bird's beak anomaly. Esophageal manometry is the most specific test and will show aperistalsis of the smooth muscle portion of the esophagus with incomplete lower esophageal sphincter relaxation. ${ }^{8}$ Regarding the identification of respiratory tract compression, imaging studies are essential for uncovering these rare findings. In both of our cases, CT scans of the chest were efficiently able to demonstrate bronchial compression.

Two theories exist regarding how dilation of the esophagus ultimately results in respiratory obstruction. The first theory postulates loss of a normal belch reflex as the cause. Normally, when the esophagus is dilated, the increased pressure causes the upper esophageal sphincter to relax. This,

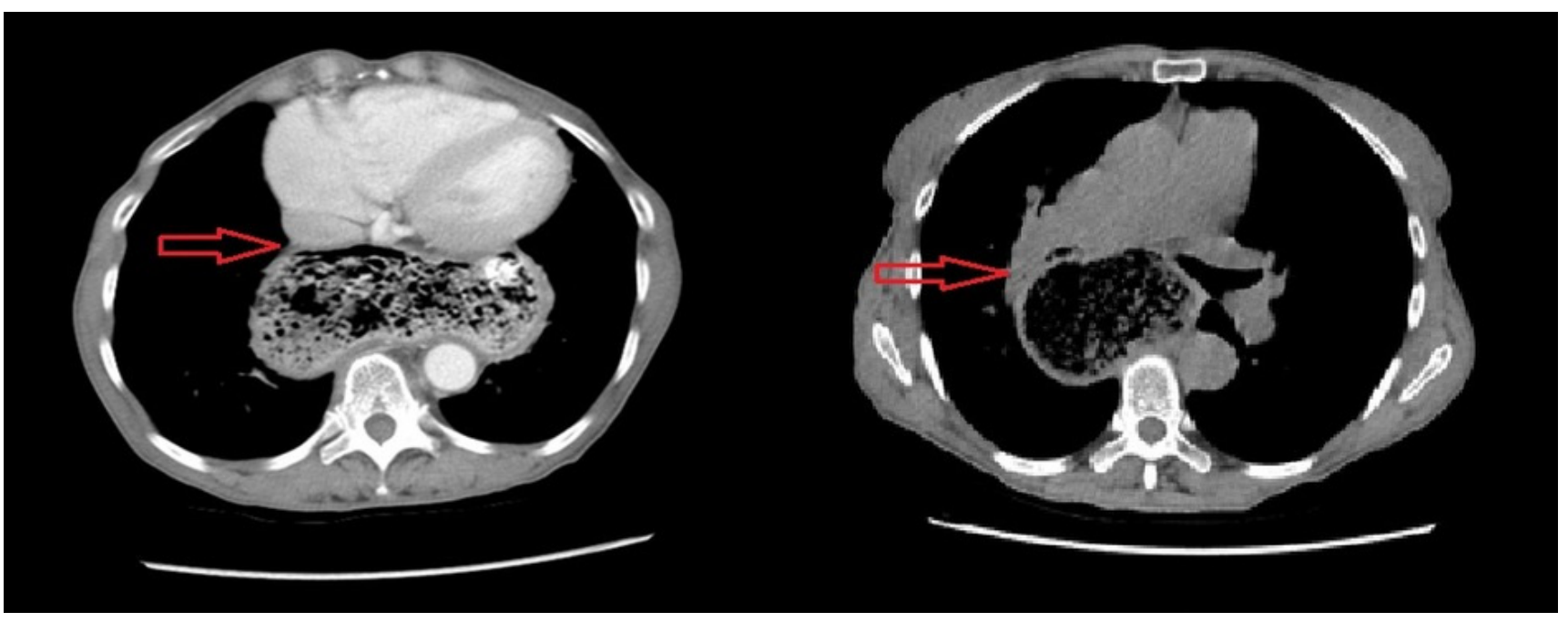

Fig. 3. Chest CT image (axial view) showing a severely dilated esophagus measuring up to $7.4 \times 7.8 \mathrm{~cm}$ in diameter and occlusion of the right middle lobe bronchus (arrows) secondary to the mass effect of the dilated esophagus. CT, computed tomography.

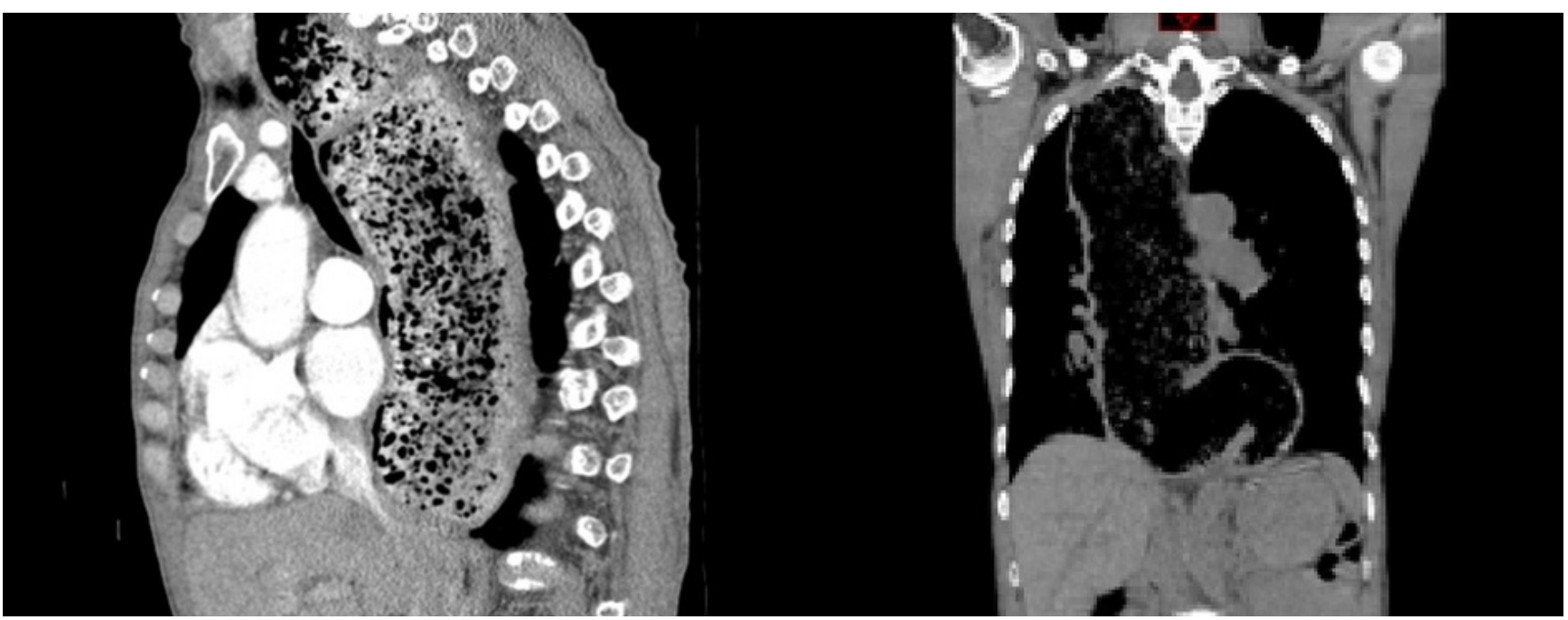

Fig. 4. Chest CT image (sagittal and coronal respectively) showing a severely dilated esophagus. CT, computed tomography. 
in turn, results in expulsion of air, which is known as the belch reflex. Failure of this reflex will result in unopposed dilation of the esophagus. ${ }^{7}$ The second theory concerns superior displacement of esophageal lumen into cricopharyngeus muscle. This occurrence causes a clamping effect on the upper esophageal sphincter, which leads to air entrapment, increased intraesophageal pressure, and ultimately results in worsening esophageal dilation. ${ }^{9}$

Multiple options are available to alleviate the respiratory symptoms of achalasia. Andolfi et al. ${ }^{10}$ conducted a study on 67 patients with respiratory symptoms secondary to achalasia. In their study, laparoscopic Heller myotomy successfully alleviated respiratory symptoms in $92.5 \%$ of these patients. Cases have also been reported that responded well to pneumatic dilation. Gupta et al. ${ }^{11}$ compiled the records of 17 achalasia patients with abnormal pulmonary function test results and found after pneumatic dilation, close to half of these patients demonstrated normalization of pulmonary function tests. To our knowledge, no study has supported the use of botulinum injections rather than the two previously mentioned modalities to alleviate respiratory symptoms in achalasia.

We would be remiss not to mention that both of our patients had a history of heroin abuse. It is generally known opiate use causes constipation, but its relationship with the esophagus is obscure. Chronic opiate use has been shown to pathologically decrease lower esophageal sphincter relaxation and to cause sphincter hypertonia. ${ }^{12}$ Ravi et al. ${ }^{13}$ conducted a retrospective, comparative cohort study on opiate use in 56 patients with achalasia and showed patients on opiates had a higher likelihood of suffering from type III achalasia. This subtype of achalasia is characterized by spastic aperistaltic contractions within the esophageal body and is the most severe subtype, in which treatment fails in approximately $70 \%$ of patients. $^{14}$

In conclusion, esophageal compression of respiratory structures is an exceedingly rare, but significant complication of achalasia. Early recognition of this disorder based on imaging findings and prompt treatment by Heller myotomy or pneumatic dilation can prevent the development of respiratory compromise in asymptomatic patients. It is also important to identify and counsel patients on modifiable risk factors such as opiate consumption shown to worsen disease progression and response to treatment.

\section{REFERENCES}

1. Ali HA, Murali G, Mukhtar B. Respiratory failure due to achalasia cardia. Respir Med CME 2009;2:40-43.

2. Ates F, Vaezi MF. The pathogenesis and management of achalasia: current status and future directions. Gut Liver 2015;9: 449-463.

3. Pandolfino JE, Gawron AJ. Achalasia: a systematic review. JAMA 2015;313:1841-1852.

4. Khan AA, Shah SW, Alam A, et al. Achalasia esophagus; presenting as acute air way obstruction. J Pak Med Assoc 2007;57:423-425.

5. Bello CT, Lewin JR, Norris CM, Farrar GE Jr. Achalasia (cardiospasm); report of a case with extreme and unusual manifestations. Ann Intern Med 1950;32:1184-1190.

6. Hifumi T, Okada I, Inoue J, Koido Y. Cardiopulmonary arrest owing to oesophageal achalasia recovered completely with cardiopulmonary resuscitation followed by therapeutic hypothermia. BMJ Case Rep 2013;2013:bcr2012008378.

7. Becker DJ, Castell DO. Acute airway obstruction in achalasia. Possible role of defective belch reflex. Gastroenterology 1989; 97:1323-1326.

8. Eckardt AJ, Eckardt VF. Treatment and surveillance strategies in achalasia: an update. Nat Rev Gastroenterol Hepatol 2011;8: 311-319.

9. Massey BT, Hogan WJ, Dodds WJ, Dantas RO. Alteration of the upper esophageal sphincter belch reflex in patients with achalasia. Gastroenterology 1992;103:1574-1579.

10. Andolfi C, Kavitt RT, Herbella FA, Patti MG. Achalasia and respiratory symptoms: effect of laparoscopic heller myotomy. J Laparoendosc Adv Surg Tech A 2016;26:675-679.

11. Gupta M, Ghoshal UC, Jindal S, Misra A, Nath A, Saraswat VA. Respiratory dysfunction is common in patients with achalasia and improves after pneumatic dilation. Dig Dis Sci 2014;59: 744-752.

12. González ES, Bellver VO, Jaime FC, Cortés JA, Gil VG. Opioid-induced lower esophageal sphincter dysfunction. J Neurogastroenterol Motil 2015;21:618-620.

13. Ravi K, Murray JA, Geno DM, Katzka DA. Achalasia and chronic opiate use: innocent bystanders or associated conditions? Dis Esophagus 2016;29:15-21.

14. Pandolfino JE, Kwiatek MA, Nealis T, Bulsiewicz W, Post J, Kahrilas PJ. Achalasia: a new clinically relevant classification by high-resoIution manometry. Gastroenterology 2008;135:1526-1533. 